\title{
Prevalence of violence and associated factors among Youth in Northwest Ethiopia: Community- based Cross-sectional study.
}

\section{Alehegn Bishaw Geremew}

University of Gondar

Abebaw Addis Gelagay

University of Gondar

Telake Azale Bisetegn

University of Gondar

Yohannes Ayanaw Habitu

University of Gondar

Solomon Mekonen Abebe

University of Gondar

\section{Eshetie Melese Biru}

University of Gondar

\section{Temiro Azanaw Mekonen}

Health Department Gondar

Yilikal Tiruneh Ayele

Amhara National Regional Health Bureau

Hedija Yenus Yeshita ( $\sim$ Kedijayenus@gmail.com )

University of Gondar College of Medicine and Health Sciences

\section{Research article}

Keywords: Violence, Youth, Physical violence, Sexual violence, Psychological violence

Posted Date: March 31st, 2020

DOl: https://doi.org/10.21203/rs.3.rs-17582/v2

License: (c) (i) This work is licensed under a Creative Commons Attribution 4.0 International License.

Read Full License 


\section{Abstract}

Background Violence as a known serious public health problem affects people in all stages of life, from childhood to the elderly. In society, one of the most visible forms of violence is young people violence, whereas they, adolescents and young adults, are the main victims of such violence. There was limited information on the burden of violence and factors among this age group. Therefore, this study aimed to determine the prevalence of violence and its associated factors among youth in Northwest, Ethiopia. Methods A community-based cross-sectional study design was conducted to estimate the magnitude of violence among youth in Northwest, Ethiopia. The calculated sample size was 1765. A structured and pretested interviewer administered questionnaire was used to collect the data. A multi-stage cluster sampling technique was employed to get the study participants. Data were entered using Epi Info version 7 and then exported to STATA 14 for data analysis. The bivariate logistic regression model was employed to identify associated factors. An adjusted odds ratio with a $95 \%$ confidence interval was used to determine factors associated with violence. Results From the total 1765 representatives of the youth population, 1597 (90.5\%) youth participated in the study. Overall, the prevalence of violence among youth aged 15-24 years for the last 12 months was $21.5 \%$. In the multivariate logistic regression model, factors significantly associated with violence were being married and divorced (AOR=1.77, 95\% Cl: 1.13, 2.79) and (AOR=5.67, 95\% Cl: 2.93, 10.99), respectively, Living with mother's only ( $\mathrm{AOR}=1.85,95 \% \mathrm{Cl}: 1.28$, 2.66) and father's only (AOR=2.45, 95\% Cl: 1.30, 4.63), and substance use (AOR=2.38, 95\% Cl: 1.56, 3.66). Conclusions The prevalence of violence among youth was high compared to other studies. Special emphasis should be given to reduce the burden of youth violence and preventing and controlling the identified factors by modifying the existing policies/strategies or developing new strategies and interventions program. Keywords: Violence, Youth, Physical violence, Sexual violence, Psychological violence

\section{Background}

The World report on violence defines violence as, "the intentional use of physical force or power, threatened or actual, against another person or a group or community that either result in or has a high likelihood of resulting in injury death, psychological harm, mal-development or deprivation"[1,2].

Violence as a known serious public health problem affects people in all stages of life, from childhood to the elderly [3]. In society, one of the most visible forms of violence is young people violence, whereas they, adolescents and young adults, are the main victims of such violence [4]. It is estimated that each year, 200,000 homicides occur in this age group in the world. Nearly all of these deaths occur in low and middle-income countries and the majority of victims (83\%) are males [2].

Youth violence often occurs alongside other types of violence. For instance, maltreated children are themselves at increased risk in later life of either perpetrating or becoming the victims of multiple types of violence - including suicide, sexual violence, youth violence, and intimate partner violence. The same set 
of factors - such as harmful levels of alcohol use, family isolation and social exclusion, high unemployment, and economic inequalities - have been shown to underlie different types of violence [5].

Violence is among the top five leading causes of death for young people aged 10-29 [6] and the elimination of violence is foreseen in the United Nations Agenda Sustainable Development Goals by 2030 $[3,7]$. Youth violence includes physical, psychological and sexual abuse, neglect, commercial or other exploitation of children (e.g., labor exploitation, forced marriage, forced criminality, domestic servitude, child soldiers), "resulting in actual or potential harm to the child' health, survival, development or dignity in the context of establishing a relationship, responsibility, trust or power" $[8,9]$.

Victims are not the only heirs of youth violence, but also deeply harm their families, friends, and communities. A great increase in the costs of health and welfare criminal justice services decreases the value of property in areas where it occurs, disrupts a range of essential services, reduces productivity, and generally undermines the fabric of society are imposed consequences of youth violence [2].

There was limited information on the burden of violence and associated factors among this age group. Therefore, measuring the burden of this problem and determinants is important to develop strategies and policies to prevent violence and manage cases. Additionally, it will give directions for researchers to conduct further research to develop or modify the existing policies and strategies for preventing and controlling violence among this age group.

\section{Literature review on the prevalence of youth violence}

The burden of youth violence is highest in low and middle-income countries [2]. A study done in Serbia violence among youth was 13.4\% [10], China 13.2\% [11], and DHS in Ethiopia 27\% [12]. The World Health Organization (WHO) based on data from selected twenty countries in low and middle-income regions reported that an average of $47 \%$ of boys and $26 \%$ of girls participated in physical fighting during the past 12 months. It means that nearly one in two males reported involvement in physical fighting. In this systematic review, the lowest physical fighting between twenty studied countries was for females in Myanmar (8\%), whereas, the highest rates are reported for boys in Samoa (73\%) [2]. A study conducted in Isfahan, Iran, having physical violence (past year) among boys and girls was $53.4 \%$ and $24.0 \%$ in middle school and $42.4 \%$ and $18.1 \%$ in high school respectively. The prevalence of physical violence was higher in middle school students than high school students [13]. In Ethiopia, nearly $16 \%$ of male college students reported physically abusing an intimate partner or non-partner [14]. Twenty-four percent of ever-married women have experienced spousal physical violence, with $17 \%$ experiencing this type of violence in the past 12 months [12].

Worldwide, around 15 million adolescent girls aged 15 to 19 have experienced forced sex in their lifetime; 9 million of these girls were victimized within the past year [15]. The reported prevalence of sexual violence among young people in dating relationships varies from $1.2 \%-32.9 \%$ for females and from $1 \%-$ $19 \%$ among boys in North America and Europe [16]. According to demographic and health survey data for selected low and middle-income countries, the percentage of girls aged 15-19 years who have ever 
experienced forced sexual intercourse ranges from zero among adolescent girls in Kyrgyzstan, to $22 \%$ among girls in the same age range in Cameroon. Among girls and women aged 15-49 years, the percentage reporting forced sexual initiation ranges from $1 \%$ in Timor- Leste to $29 \%$ in Nepal [17], in Uganda, 35\% [18] and EDHS report, seven percent of women age 15-49 reported that they have experienced sexual violence in the past 12 months, five percent of women had experienced sexual violence by age 18 , including $2 \%$ who had experienced sexual violence by age 15 [12].

A study in Serbia showed that (in the family and on the street) $2.8 \%$ and $5.3 \%$ were victims of psychological violence, respectively [10]. A similar study conducted in Isfahan, Iran, distribution of violent behavior among studied students; Youth threatened by someone in the last 12 months among boys and girls $25 \%$ and $8 \%$ in middle school and $19.1 \%$ and $6.1 \%$ in high school, respectively [13]. The experience of any emotional violence in among ever-married women age $15-49$ years was $20.2 \%$ [12].

\section{Factors associated with youth violence}

The associations of socio-demographic and other factors with violence; being raised in poverty has been found to contribute a greater likelihood of involvement in violence, and poverty both in the community and at the level of individual households has been shown to predict violence $[2,19]$.

A study conducted in Serbia, predictors of violence victimization were male gender, lack of close friends and urban settlements [10]. The youngest women (age 15-19), women with no children, and never-married women are less likely to have experienced violence [12]. Young men are at far greater risk than females for becoming perpetrators and victims of youth violence. About $90 \%$ of fatal violence is perpetrated by males and $83 \%$ of all youth homicide victims are males. Female involvement in youth violence resulting in non-fatal physical injures remains inadequately studied in many countries. In the USA, females represent $20 \%$ of all arrests for violent crime among those aged $10-29$ years [20].

Youth violence perpetration and victimization are related to low academic achievement. Those who are involved in youth violence show lower educational performance and are more at risk of school dropout or truancy [21]. At the individual level, young people who start drinking early and drink frequently are at increased risk of perpetrating or being a victim of youth violence. At community and society levels, crowded and poorly managed drinking venues contribute to increased aggression among drinkers [22]. Several studies confirm that violent incidents often occur in situations of alcohol intoxication $[23,24]$.

DHS in Ethiopia, all forms of spousal violence are higher among divorced/separated/widowed women, women with no education with the level of husbands/partners alcohol consumption. Experiences of physical violence by urban-rural residence, rural women are only somewhat more likely than urban women to have experienced physical violence [12].

There are no or limited studies conducted to assess violence against young people and its determinants in the study area as well as in Ethiopia. Even some studies conducted previously focused only on the reproductive health problems of young people; yet, which does not address violence against young 
people in both sex groups. Hence, the present study was designed to determine the prevalence of violence and related factors among youth in Northwest Ethiopia. Thus, the findings of this study contribute to public health researchers and policymakers to promote further research and develop or modify strategies designed to reduce violence.

\section{Methods}

\section{Study design}

A community-based cross-sectional study design was conducted to estimate the magnitude of violence and associated factors among young people aged 15-24 years.

\section{Study Setting and period}

This study was done in Central, West and North Gondar Zones. A total of 24 woredas and 1 city administration present in the three zones: Central Gondar zone have 13 woredas, North Gondar Zone 7 woredas, and West Gondar zone 4 woredas. The total number of kebeles in the three zones is 546 having a total population of $3,654,920$ populations, from this $1,847,631$ was males and $1,807,289$ females [25]. The study was done from September 2018 to June 2020.

\section{Source and Study Population}

The source population of the study was young people aged 15-24 years living both in rural and urban settings in central, west and north Gondar Zone whereas youth in the selected kebeles of in these rural and urban settings were the study population.

\section{Sample Size calculation and sampling techniques}

The sample size of the study was calculated by considering the prevalence of a study conducted in Ethiopia $27.0 \%$ [11], Significance level $=95 \%$ Margin of error $=3 \%$, and Design effect $=2$ the total sample size was 1681. By considering the non-response rate of $5 \%$, the final sample size was 1765 .

A multistage cluster sampling technique was employed to get the study participants. Firstly, two woredas from the central Gondar zone, one woreda from each North Gondar zone and west Gondar zone were selected. Secondly, three kebeles were selected from the selected woredas. From each kebele, three clusters (Ketena/Gote) were randomly selected. The non-proportional or equal allocation was considered to get households in each cluster and eligible study participants were interviewed.

\section{Operational Definitions}

Violence is defined by the World Health Organization "the intentional use of physical force or power, threatened or actual, against oneself, another person, or against a group or community, that either result in or has a high likelihood of resulting in injury, death, psychological harm, mal-development or 
deprivation" Any of the specified acts of physical, sexual, or emotional violence in the past 12 months preceding the survey $[1,12]$.

Emotional violence: Say or do something to humiliate you in front of others; threaten to hurt or harm you or someone close to you; insult you or make you feel bad about yourself [12].

Physical violence: Push you, shake you, or throw something at you; slap you; twist your arm or pull your hair; punch you with his/her fist or with something that could hurt you; kick you, drag you, or beat you up; try to choke you or burn you on purpose; or threaten or attack you with a knife, gun, or any other weapon [12].

Sexual violence is defined as physical force you to have sexual intercourse with him even when you did not want to; physically force you to perform any other sexual acts you did not want to; force you with threats or in any other way to perform sexual acts you did not want to [12].

\section{Data collection method and procedure}

Twenty four data collectors, who were nurses and midwives working in public health institutions (Health Centers) in the selected woredas especially those who were working in a youth-friendly clinic, and five supervisors (one supervisor per woreda) who were at least degree holders involved during data collection. The training was given for five days for data collectors and supervisors. After getting the consent, the data were collected from study participants through an interviewer-administered questionnaire. The supervisor and investigators were the overall supervision of the data collection process.

\section{Quality assurance mechanisms}

To assure data quality, training was given for data collectors and supervisors on the objective of the study, consent and confidentiality, and data collection technique/approaches. The tool was pretested on $5 \%$ of the sample size outside the data collection site. Amendment was made after the pre-test. Close supervision was undertaken during data collection both by supervisors and investigators, and the filled questionnaire was checked for completeness before data entry.

\section{Statistical analysis}

An Epi Info version 7 was used for data entry and transferred to STATA 14 for data management and final analysis. First, descriptive analysis was done to determine the problem of violence among young people. Second, binary logistic regression was used to do both bivariable and multivariable analyses to see the association between covariates and violence. Odds ratio with $95 \% \mathrm{Cl}$ and P-value $<0.05$ was used to determine the presence and the strength of the association between dependent and independent variables.

\section{Results}




\section{Socio-demographic Characteristics of Youth in Northwest, Ethiopia}

From the total 1765 representative sample of the youth population, 1597 (90.5\%) young people participated in the study. From the total respondents, $50.7 \%$ was found in central Gondar, $68.1 \%$ of the participant's age in the study was below 20 years, the mean and median age of the participants were 19.19 and 19 respectively, with an $S D \pm 2.85$. More than half of the respondents $51.2 \%$ were females. The majority of respondents was in rural settlements $53.5 \%$ and had primary education $46.6 \%$ (Table 1 ).

Table1. Socio-demographic characteristics of youth Northwest Ethiopia

\begin{tabular}{lcc} 
Variable name & Frequency & Percentage \\
\hline Zone & & \\
\hline Central Gondar & 810 & 50.7 \\
\hline North & 523 & 32.8 \\
\hline West Gondar & 264 & 16.5 \\
\hline Age & & \\
\hline$<20$ & 1087 & 68.1 \\
\hline 20 and above & 510 & 31.9 \\
\hline Sex & & \\
\hline Male & 780 & 48.8 \\
\hline Female & 817 & 51.2 \\
\hline Residence & & \\
\hline Rural & 854 & 53.5 \\
\hline Urban & 743 & 46.5 \\
\hline Religion & & \\
\hline Orthodox & 1483 & 92.9 \\
\hline Muslim & 104 & 6.5 \\
\hline Others & 10 & 0.6 \\
\hline Marital status & & \\
\hline Single & 1721 & 79.6 \\
\hline Married & 283 & 17.7 \\
\hline Divorced & 43 & 2.7 \\
\hline Educational level & & \\
\hline Unable to read and write & 114 & 7.1 \\
\hline Primary education & 739 & 46.3 \\
\hline Secondary education & 550 & 34.4 \\
\hline Higher & 194 & 12.2 \\
\hline Currently attending school & & \\
\hline No & 611 & 38.3 \\
\hline Yes & 986 & 61.7 \\
\hline Occupation & & \\
\hline Unemployed & 1356 \\
\hline Employed & 241 & 13.9 \\
\hline Living arrangement & & \\
\hline Mother and father & 158 \\
\hline Mother only & & \\
\hline Father only & & \\
\hline Husband/wife & & \\
\hline Relative/sister or brother & & \\
\hline Others & & \\
\hline Alone & & \\
\hline
\end{tabular}




\section{Socio-demographic Characteristics of Youth Parents in Northwest. Ethiopia}

The majority of their parents (mother and father) were (88.6\%) and (80.2\%) alive, respectively. The educational status of their parent's not educated, mother's (77.5\%) and father's (37.7\%) (Table 2).

Table 2. Socio-demographic characteristics of youth parent's Northwest, Ethiopia

\begin{tabular}{|c|c|c|}
\hline Variable name & Frequency & Percentage \\
\hline \multicolumn{3}{|l|}{ Mother alive } \\
\hline No & 182 & 11.4 \\
\hline Yes & 1415 & 88.6 \\
\hline Mothers education & 1415 & \\
\hline Cannot read and write & 997 & 70.8 \\
\hline Read and write & 223 & 15.8 \\
\hline Primary education & 116 & 8.2 \\
\hline Secondary education & 53 & 3.7 \\
\hline College and above & 26 & 1.8 \\
\hline \multicolumn{3}{|l|}{ Mothers occupation } \\
\hline Housewife & 1237 & 77.5 \\
\hline Merchant & 94 & 5.9 \\
\hline Government employee & 35 & 2.2 \\
\hline Private employee & 9 & 0.6 \\
\hline Daily laborer & 26 & 1.6 \\
\hline Others & 14 & 0.9 \\
\hline \multicolumn{3}{|l|}{ Father alive } \\
\hline No & 316 & 19.8 \\
\hline Yes & 1281 & 80.2 \\
\hline \multicolumn{3}{|l|}{ Fathers education } \\
\hline Cannot read and write & 483 & 37.7 \\
\hline Primary education & 657 & 51.3 \\
\hline Secondary education & 99 & 7.7 \\
\hline Higher education & 41 & 3.2 \\
\hline \multicolumn{3}{|l|}{ Father's occupation } \\
\hline Merchant & 245 & 15.3 \\
\hline Government employee & 98 & 6.1 \\
\hline Private employee & 35 & 2.2 \\
\hline Daily laborer & 30 & 1.9 \\
\hline Farmer & 858 & 53.7 \\
\hline Others & 15 & 0.9 \\
\hline \multicolumn{3}{|l|}{ Number of families } \\
\hline$<5$ & 1018 & 63.7 \\
\hline $5-9$ & 557 & 34.9 \\
\hline 10 and above & 22 & 1.4 \\
\hline \multicolumn{3}{|l|}{ Wealth index } \\
\hline First(lowest) & 319 & 20 \\
\hline Second & 320 & 20 \\
\hline Third & 319 & 20 \\
\hline Fourth & 320 & 20 \\
\hline Highest & 319 & 20 \\
\hline
\end{tabular}




\section{The prevalence of violence among youth 15 to 24 years old in the past 12 months}

Overall, the prevalence of violence among youth for the last 12 months was $21.5 \%$. Youth hit /slapped or thrown something (physical violence), scared/intimidated (psychological violence), and exposed to sexual violence for the last 12 months were $8.3 \%, 13.6 \%$, and $3.4 \%$, respectively (Table 3 ).

Table 3: Percentage of youth violence and their personal behavior Northwest, Ethiopia Variable Frequency Percentage

One people scare or intimidate you for the last 12 months

No

Yes

Intimidate for the last 3 months

No 86

Yes 131

60.4

Threatened to hurt you for the last 12 months

\begin{tabular}{lcc} 
No & 1471 & 92.1 \\
\hline Yes & 126 & 7.9 \\
\hline Threatened to hurt you for the last 3 months & 40 & 31.7 \\
\hline No & 86 & 68.3
\end{tabular}

Hit /slapped you or thrown something to you for the last 12 months/physical violence

No 1465

91.7

Yes

Hit /slapped you or thrown something to you the last 3months

No

Yes

Forced or pressured you to have sexual intercourse for the last 12 months/sexual violence

No

Yes

Forced or pressured you to have sexual intercourse for the last 3months

No

Yes

Violence within the last 12 months

No

Yes

Violence within the last 3months

No

Yes

Ever use substance

No

Yes

\section{3}

89

32.6

67.4

1543

54

96.6

3.4

32

59.3

22

40.7

1254

343

78.5

21.5

1371

85.8

226

14.2

1489

93.2

108

6.8 


\section{Factors associated with youth violence}

In the bivariate logistic regression analysis, a statistically significant association $(p<0.05)$ was observed between youth violence and the independent variables. The odds of being married and divorced (AOR= $1.77,95 \% \mathrm{Cl}: 1.13,2.79)$ and (AOR=5.67, 95\% Cl: $2.93,10.99)$, respectively associated with violence among youth compared to unmarried or single. Living with mother only $(A O R=1.85,95 \% \mathrm{Cl}: 1.28,2.66)$, father's only (AOR $=2.45,95 \% \mathrm{Cl}: 1.30,4.63)$ and husband/wife (AOR=0.44, 95\% Cl: $0.25,0.76)$ were associated with violence compared to living with both parents. In this study substance use is 2.2 times more likely associated with youth violence compared to non-substance use (AOR=2.38, 95\% $\mathrm{Cl}: 1.56$, 3.66) (Table 4).

Table 4: Factors associated with violence among youth in Northwest, Ethiopia

riable name Violence for the past 12 months COR/CI

AOR P-value No Yes

\begin{tabular}{|c|c|c|c|c|c|}
\hline \multicolumn{6}{|l|}{$\mathbf{x}$} \\
\hline ile & 601 & 179 & $1.19(0.13,1.51)$ & & \\
\hline male & 653 & 164 & 1 & 1 & \\
\hline \multicolumn{6}{|l|}{ arital status } \\
\hline igle & 1010 & 261 & 1 & 1 & \\
\hline arried & 224 & 59 & $1.02(0.74,1.40)$ & $1.77(1.13,2.79)$ & $0.012^{*}$ \\
\hline vorced & 20 & 23 & $4.45(2.41,8.23)$ & $5.67(2.93,10.99)$ & $0.0001^{* * *}$ \\
\hline \multicolumn{6}{|l|}{ ucational level } \\
\hline t educated & 95 & 19 & $0.59(0.33,1.07)$ & & \\
\hline imary education & 571 & 168 & $0.87(0.60,1.26)$ & & \\
\hline condary education & 443 & 107 & $0.72(0.49,1.05)$ & & \\
\hline gher education & 145 & 49 & 1 & 1 & \\
\hline \multicolumn{6}{|c|}{ rrently attending school } \\
\hline 1 & 469 & 142 & $1.18(0.93,1.51)$ & & \\
\hline $\mathrm{s}$ & 785 & 201 & 1 & 1 & \\
\hline \multicolumn{6}{|l|}{ th whom you live } \\
\hline ther and father & 610 & 148 & 1 & 1 & \\
\hline ther only & 126 & 58 & $1.89(1.33,2.78)$ & $1.85(1.28,2.66)$ & $0.001 * * *$ \\
\hline ther only & 28 & 17 & $2.50(1.33,4.69)$ & $2.45(1.30,4.63)$ & $0.006^{* *}$ \\
\hline tsband/wife & 188 & 34 & $0.76(10.49,1.12)$ & $0.44(0.25,0.76)$ & $0.004 * *$ \\
\hline lative/sister/brother & 79 & 26 & $1.36(0.84,2.19)$ & $1.35(0.83,2.19)$ & 0.223 \\
\hline hers & 61 & 9 & $0.61(0.29,1.25)$ & $0.49(0.23,1.05)$ & 0.065 \\
\hline one & 162 & 51 & $1.29(0.90,1.86)$ & $0.91(0.62,1.35)$ & 0.652 \\
\hline \multicolumn{6}{|l|}{ salth index } \\
\hline st(lowest) & 255 & 64 & $0.75(0.52,1.09)$ & & \\
\hline cond & 255 & 65 & $0.76(0.53,1.10)$ & & \\
\hline ird & 245 & 74 & $0.90(0.63,1.30)$ & & \\
\hline urth & 260 & 60 & $0.69(0.47,1.01)$ & & \\
\hline ghest & 239 & 80 & 1 & 1 & \\
\hline \multicolumn{6}{|l|}{ bstance use } \\
\hline 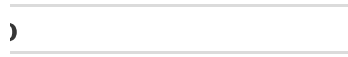 & 1186 & 303 & 1 & 1 & \\
\hline $\mathbf{s}$ & 68 & 40 & $2.30(1.53,3.47)$ & $2.38(1.56,3.66)$ & $0.0001 * * *$ \\
\hline
\end{tabular}




\section{Discussion}

Violence is the leading cause of morbidity as well as mortality among young or youth populations. In this study, the prevalence of violence among youth was $21.5 \%$. This finding was in line with the study conducted in Ethiopia, 27\% [12], but it was higher than a study conducted in Serbia 13.4\% [10], China $13.2 \%$ [11] and in Ethiopia 16\% [14]. The higher finding in our study might be most of the youth were unemployed and living in lower socioeconomic status that imposed them on substance use, commits crime and violence.

The prevalence of youth violence among males and females was $22.9 \%$ and $20.1 \%$, respectively. This study finding was higher compared to study in Serbia and China; the prevalence of youth violence among males and females was $15.5 \%$ for males and $11.1 \%$ for females in Serbia [10] and China [11] among students who reported being threatened or injured with a weapon in school was ( $15.7 \%$ vs. $10.5 \%)$. This variation could be a difference in the study setting and population characteristics. The higher finding in our study is due to a high rate of unemployment among the youth population and currently, there is political instability in the country including the study area.

In this study, the prevalence of physical violence among youth in the past 12 months was $8.3 \%$. It was comparable with a study done in Serbia 7.3\% [10], Myanmar (8\%) [2], and in Malaysia, 11.8\% [26], but lower than a review done in twenty countries (in low and middle-income regions) reported that an average of $47 \%$ of boys and $26 \%$ of girls, the highest rates for boys in Samoa (73\%) [2], and a study in Isfahan, Iran among boys and girls $53.4 \%$ and $24.0 \%$ in middle school, $42.4 \%$ and $18.1 \%$ in high school, respectively [13] and in Uganda 59\% [18]. This variation was due to differences in population characteristics and settings. The review of the above studies was done on the riskiest regions (in low and middle-income) and targets (school students). Large segments of adolescents or youth found in the school compound were much more likely to encounter violence from their peers.

In this study, the prevalence of sexual violence among youth was $3.4 \%$. This finding was consistent with a study done in Uganda 5.6\% [27] and Ethiopia 7\% [12]. But lower than a review done in Nepal 29\% and Cameroon 22\% [17] and Uganda 35\% [18]. This difference might be due to the study setting and period. Currently, the violators of sexual violence and their legal punishment were exhibited through the media that might impede others to commit sexual violence.

The prevalence of scared/intimidated (psychological violence) in this study was $13.6 \%$. It was higher than a study done in Serbia $2.8 \%$ [10], but this finding was lower than a study in Isfahan, Iran among boys $25 \%$ in middle school and $19.1 \%$ in high school, respectively [13] and similar study in the same country among adolescents and youth reported to be between $30 \%$ and $65.5 \%$, respectively [28] and in Uganda $33.3 \%$ [18]. This difference could be a difference in the study area, setting, and participants; a large segment of adolescents or youth found in the school compound were much more likely to encounter 
violence from their peers, and the biological differences of the participants might explain some differences in levels of violence between boys and girls.

In the multivariate logistic regression proved that the odds of being married and divorced were 1.8 and 5.7 times more likely associated with violence among youth compared to unmarried or single, respectively. Never-married women are less likely to have experienced violence. This finding was inconsistent with a study done in Serbia [10] and DHS in Ethiopia [12]. The possible explanation for this difference could be married youth or divorced were unemployed and those who were married also economically dependent on their husband or husband's parents that led them to conflict and exposed to violence.

Living with mother only or father alone was 2 to 2.5 times more likely associated with violence compared to living with both parents. This finding was consistent with a study done in Goa, India [29] and Arbaminch town, Gammo Goffa zone, Southern Ethiopia [30]. The possible explanation could be, parental monitoring and supportiveness minimize their chance of exposure to risks of substance use and violence.

In this study substance use was 2.4 times more likely associated with youth violence compared to nonsubstance use. The finding of this study corroborated with studies done in different countries $[22,23,24$, and 29]. This is because alcohol use directly affects cognitive and physical functioning and can reduce self-control and the ability to process information and assess risks. It can increase impulsiveness and make particular drinkers more likely to engage in violent behavior.

Limitation of this study: The main limitations of this study relate to the cross-sectional design, which does not allow us to determine the direction of the causality of the detected associations. It doesn't measure the amount and frequency of substance use among the respondents. There might be recall bias.

\section{Conclusions}

The prevalence of violence among youth was high compared to other studies. Special emphasis should be given to reduce the burden of youth violence and preventing and controlling the identified factors by modifying the existing policies/strategies or developing new strategies and interventions program.

\section{List Of Abbreviations}

AOR: Adjacent Odds Ratio

Cl: Confidence Interval

COR: Crude Odds Ratio

DHS: Demographic and Health Survey 
EDHS: Ethiopia Demographic and Health Survey

SD: Standard Deviation

UoG: University of Gondar

USA: United States of America

WHO: World Health Organization

\section{Declarations}

\section{Ethics approval and consent to participate}

Ethical clearance was obtained from the Institutional Review Board of UoG. Permission letter to conduct the study was obtained from central, west and north Gondar Zone Health department. Assent and informed consent were obtained from potential study participants and their families or guardians accordingly. It was explained to the participants that the selection of the study is random and they have the right not to participate or withdraw from the study at any time. To ensure confidentiality, their name and other personal identification were not registered in the format.

Consent for publication: Not applicable.

Availability of data and materials: "The datasets used and/or analyzed during the current study will be available from the corresponding author upon reasonable request".

Competing interests: Authors declare that they have no conflict of interest.

Funding: Not available

Authors' contributions: Abebaw Addis Gelagay and Alehegn Bishaw Geremew wrote the proposal, and all authors involved in data analysis and drafted the paper. Finally, we read and approved the final manuscript.

\section{Acknowledgments}

The authors would like to acknowledge the University of Gondar for encouraging us to conduct this research. We have extended our gratitude for the data collectors and supervisors for their unreserved work. The authors also forwarded thanks to the study participants for providing us all the necessary information.

\section{References}


1. Krug EG, Mercy JA, Dahlberg LL, Zwi AB. The world report on violence and health. The lancet. 2002;360(9339):1083-8.

2. Organization WH. People-centred and integrated health services: an overview of the evidence: interim report. World Health Organization, 2015.

3. Butchart A, Mikton C, Dahlberg LL, Krug EG. Global status report on violence prevention 2014. BMJ Publishing Group Ltd; 2015.

4. Reza A, Mercy JA, Krug E. Epidemiology of violent deaths in the world. Inj Prev. 2001;7:104-11.

5. Mercy JA, Butchart A, Rosenberg ML, Dahlberg L, Harvey A. Preventing violence in developing countries: a framework for action. International Journal of Injury Control and Safety Promotion. 2008; 15(4):197-208.

6. Mokdad AH, Forouzanfar MH, Daoud F, Mokdad AA, El Bcheraoui C, Moradi-Lakeh M, et al. Global burden of diseases, injuries, and risk factors for young people's health during 1990-2013: a systematic analysis for the Global Burden of Disease Study 2013. The Lancet. 2016; 387(10036):2383-401.

7. United Nations. UN Sustainable Development Goals. New York, NY, USA, 2017.

8. Global Status Report on Violence Prevention 2014; World Health Organization: Geneva, Switzerland, 2014; Available online:

http://www.who.int/violence_injury_prevention/violence/status_report/2014/en/ (accessed on 31 August 2018).

9. Felitti VJ, Anda RF, Nordenberg D, Williamson DF, Spitz AM, Edwards V, et al. Relationship of childhood abuse and household dysfunction to many of the leading causes of death in adults: The Adverse Childhood Experiences (ACE) Study. American journal of preventive medicine. 2019; 56(6):774-86.

10. Obradovic-Tomasevic B, Santric-Milicevic M, Vasic V, Vukovic D, Sipetic-Grujicic S, BjegovicMikanovic $V$, et al. Prevalence and predictors of violence victimization and violent behavior among youths: a population-based study in Serbia. International journal of environmental research and public health. 2019;16 (17):3203.

11. Wang H, Du H, Bragg F, Zhong J, Yu M. Relationship of being threatened or injured with a weapon in school with suicidal ideation and attempt among school students: a school-based study in Zhejiang Province, China. BMC public health. 2018; 18(1):1405.

12. Ethiopia CSA, Macro O. Ethiopia demographic and health survey. Addis Ababa: Central Statistical Agency. 2016.

13. Golshiri P, Farajzadegan Z, Tavakoli A, Heidari K.Youth Violence and Related Risk Factors: A Crosssectional Study in 2800 Adolescents, Isfahan, Iran. Advanced Biomedical Research. 2018; 7.

14. Philpart M, Goshu M, Gelaye B, Williams MA, Berhane Y. Prevalence and risk factors of gender-based violence committed by male college students in Awassa, Ethiopia. Violence and Victims. 2009; 24(1):122-36. 
15. United Nations Children's Fund (UNICEF): Violence in the lives of children and adolescents Division of Data, Research and Policy, November 2017.

16. Leen E, Sorbring E, Mawer M, Holdsworth E, Helsing B, Bowen E. Prevalence, dynamic risk factors and the efficacy of primary interventions for adolescent dating violence: An international review. Aggression and Violent Behavior. 2013; 18(1):159-74.

17. UNICEF: A statistical analysis of violence against children.: New York; 2014.

18. MGLSD (Ministry of Gender, Labour and Social Development). Violence against children survey findings from a national survey. Kampala: Uganda; 2018. https://www.unicef.org/uganda/VACS_ Report_lores.pdf. Accessed Feb, 2019.

19. Lynch JP, Pridemore WA. Crime in international perspective. Crime and public policy. 2011:5-52.

20. Federal Bureau of Investigation. Uniform crime reports: Crime in the United Stated, Washington, DC: US Department of Justice, Federal Bureau of Investigation [cited 2015 Jun 08]. Available from: http://www.fbi.gov/about-us/cjis/ucr/crime-in-the-u.s/2013/ crime-in-the-u.s.-2013/personsarrested/persons-arrested.

21. Brener ND, Eaton DK, Flint KH, Hawkins J, Kann L, Kinchen S, et al. Methodology of the Youth Risk Behavior Surveillance System-2013. 2004.

22. Homel R, Clark J. The prediction and prevention of violence in pubs and clubs. Crime Prevention Studies. 1994;3:1-46.

23. Mattila VM, Parkkari J, Lintonen T, Kannus P, Rimpelä A. Occurrence of violence and violence related injuries among 12-18-year-old Finns. Scandinavian Journal of Public Health. 2005; 33(4):307-13.

24. Chikritzhs T, Catalano P, Stockwell T, Donath S, Ngo H, Young D, et al. Australian alcohol indicators, 1990-2001. Patterns of alcohol use and related harms for Australian states and territories. Perth: National Drug Research Institute, Turning Point 2003; 200.

25. Federal Democratic Republic of Ethiopia Central Statistical Agency. Population Projection of Ethiopia for All Regions At Wereda Level from 2014 - 2017; Addis Ababa August, 2013

26. Saminathan TA, Ganapathy SS. Prevalence and Factors Associated With Physical Abuse at Home Among School-Going Adolescents in Malaysia: A Population-Based Nationwide Study. 2019; 31(8_suppl):88s-96s.

27. Logie CH, Okumu M, Mwima S, Hakiza R, Irungi KP, Kyambadde P, et al. Social ecological factors associated with experiencing violence among urban refugee and displaced adolescent girls and young women in informal settlements in Kampala, Uganda: a cross-sectional study. Conflict and health. 2019;13:60.

28. Fakhari A, Tabatabavakili M, Javid YS, Farhang S. Family violence influences mental health of school girls in Iran: Results of a preliminary study. Asian J Psychiatr 2012; 5:24-

29. Prevalence and Correlates of Perpetration of Violence among Young People: A Population-Based Survey From Goa, India https://doi.org/10.1371/journal. pone.0221049. Asia-Pacific Journal of Public Health 2015, Vol. 27(2) NP2512- NP2520. 
30. Mekuria A, Nigussie A, Abera M. Childhood sexual abuse experiences and its associated factors among adolescent female high school students in Arbaminch town, Gammo Goffa zone, Southern Ethiopia: a mixed method study. BMC international health and human rights. 2015; 15(1):21. 